\title{
EDUCAÇÃO A DISTÂNCIA E DEFICIÊNCIA VISUAL: POSSIBILIDADES E PERSPECTIVAS
}

\section{DISTANCE EDUCATION AND VISUAL IMPAIRMENT: POSSIBILITIES AND PROSPECTS}

COSTA, Maria Luisa Furlan

luisafurlancosta@gmail.com

Universidade Estadual de Maringá

LOZANO, Taissa Vieira

taissalozano@gmail.com

Universidade Estadual de Maringá

\begin{abstract}
RESUMO Este artigo discute a relação da educação a distância no Ensino Superior com a inclusão de alunos deficientes visuais. Esses alunos têm o direito à educação garantido por lei, mas encontram dificuldades de acesso ao processo educativo formal pelo caráter histórico de exclusão dos deficientes. Os objetivos específicos abordam as principais facilidades e dificuldades encontradas pelos deficientes visuais e a possibilidade e a necessidade de mediação exercida pelo professor na modalidade de educação a distância. A metodologia, pautada na análise bibliográfica, buscou relacionar tais aspectos, discutindo essa temática para compreender que fatores contribuem ou não para o processo de aprendizagem e desenvolvimento do deficiente visual em cursos a distância, quais são as formas de reverter os fatores negativos encontrados e quais os avanços em relação à inclusão do deficiente. As principais dificuldades encontradas por esse alunado são as aulas preparadas para aqueles que não têm deficiência, e a facilidade encontrada em sua maioria é a utilização das tecnologias por meio dos softwares que facilitam o acesso às informações impressas.
\end{abstract}

PALAVRAS-CHAVE: Deficiência visual. Educação a distância. Educação especial.

ABSTRACT This article presents a discussion on the relationship of distance education in higher education with the inclusion of visually impaired students. Students those who have the right to education guaranteed by law, but who find it difficult to access formal education process by historical character exclusion of disabled people. The specific objectives cover key facilities and difficulties encountered by visually impaired and need and the possibility of mediation exercised by the teacher in the form of distance education. A methodology based on the literature review sought to relate these aspects in discussing this subject to 
understand what factors contribute to whether or not the process of learning and development of the visually impaired in distance course, what forms of reversing the negative factors found and which advances regarding the inclusion of the disabled.

KEY-WORDS: Visual impairment. Distance education. Special education.

\section{A MODALIDADE DE EDUCAÇÃO A DISTÂNCIA NO ENSINO SUPERIOR BRASILEIRO}

A sociedade interligada por redes de tecnologia digital é resultado do desenvolvimento de softwares e tecnologias que atendem à expansão do mercado mundial. Em meio a esse processo, a educação passou por mudanças que vêm ao encontro dessa realidade (ALVES; NOVA, 2003). A educação a distância (EaD) surge para acompanhar essa demanda, pois caracteriza-se como uma modalidade de ensino não presencial que transmite o conhecimento sem a presença física de professores e alunos, com a interação possibilitada pelo uso das tecnologias de comunicação e informação (TICs). Nessa modalidade, o Ensino Superior pode chegar a lugares aonde o acesso presencial é difícil, o que democratiza e interioriza a oferta desse nível de ensino superior no Brasil.

De acordo com Bacha Filho (2003), com a revolução tecnológica e com a expansão do ensino superior nas últimas décadas, a educação a distância também ganhou força para se instalar e adentrar em um ambiente no qual as aulas eram conhecidas como presenciais.

Bacha Filho traz uma colocação relevante sobre o EaD na intenção de oferecer educação de qualidade e igualdade para todos, como se encontra na legislação brasileira:

Se os esforços para a melhoria do sistema educativo devem centrar-se na ampliação das oportunidades de aprendizagem, a EAD é um possível instrumento para concretizar políticas de equidade que aumentem as oportunidades educativas de grupos tradicionalmente marginalizados e permitam a construção de uma sociedade em que todos os cidadãos compartilhem um patamar comum de conhecimentos e códigos culturais, atenuando a injusta exclusão social. (BACHA FILHO, 2003, p. 32)

Zanatta (2010) enfatiza que apenas a partir de 1996 a EaD passou a ser considerada como possibilidade de complementação ao Ensino Fundamental 
presencial com o apoio da Lei 9394/96, cujo artigo 80 destaca que essa modalidade passou a ser relacionada a todos os níveis e modalidades de ensino, surgindo, por consequência, os encaminhamentos legais para a implementação de cursos e programas ofertados a distância. Salienta-se que para oferecer cursos em uma modalidade distinta do ensino presencial é necessário passar pelo mesmo processo exigido para os cursos considerados regulares.

Foram publicados diversos documentos para serem estabelecidos os critérios precisos e fundamentais para a legalização dessa modalidade de ensino. O último Decreto que regulamenta os artigos 80 e 81 da LDB n9394/96 é o de $n^{\circ} 5622$, que, no seu Artigo $1^{\circ}$, define educação a distância como:

[...] modalidade educacional na qual a mediação didático-pedagógica no processo de ensino e aprendizagem ocorre com a utilização de meios e tecnologias de informação e comunicação, com estudantes e professores desenvolvendo atividades educativas em lugares ou tempos diversos. (BRASIL, 2006ª apud ZANATTA, 2010, p. 31).

Com a aprovação da LDB, houve diversos aspectos que sofreram mudanças na educação brasileira, destacando-se a formação dos professores da Educação Básica, que até o momento não necessitavam de curso superior para lecionar. A LDB estipulou como prazo o final do ano de 2007 para que esses professores cursassem o Ensino Superior. De acordo com Zanatta (2010), a partir de então foi possível perceber a agilidade do Ministério de Educação e Cultura (MEC) no processo de autorização e funcionamento da educação a distância; essa rapidez relaciona-se à oportunidade desses professores cursarem Pedagogia na modalidade a distância, considerando que a quantidade de vagas presenciais ofertadas não atendia à demanda existente.

Dados apresentados por Zanatta (2010) mostram que, no Brasil, em 1997, existia apenas um curso de licenciatura pela EaD e, em janeiro de 2002, esse número era de 75 cursos; ou seja, no período de 2003 a 2006, houve um crescimento significativo da EaD. Em 2003, eram 21.873 alunos inscritos, e em 2006, esse número era de 430.229 inscritos; um crescimento de $315 \%$.

A autora ainda relata que a EaD é uma possibilidade de atender uma população crescente que espera ter acesso à educação. Entretanto, essa 
modalidade foi vista com preconceito, porque muitos a consideravam como uma educação de segunda categoria. Com o desenvolvimento das tecnologias de informação e pela necessidade do direito e acessibilidade a todos, os olhares foram mudando e atualmente o preconceito é bem menor.

Os dados do censo de 2010 revelam a expansão da EaD entre 2005 a 2009, que teve $14,6 \%$ das matrículas nacionais nessa forma de ensino; o índice do aumento nas matrículas dos cursos superiores de tecnologia (CST) de 2,3\% foi para $12,3 \%$ no mesmo período. A relação desse aumento de cursos na $\mathrm{EaD}$ demonstra como essa modalidade está ganhando espaço no campo educacional brasileiro.

Esses dados podem estar relacionados à forma de interação do professor e aluno, que não precisa acontecer apenas em sala de aula, uma vez que, na $\mathrm{EaD}$, o ato de aprender pode ser alcançado em qualquer lugar, independente da distância entre aluno e professor. As ferramentas para se alcançar esses objetivos são a utilização das tecnologias existentes direcionadas ao processo de ensino e aprendizagem a distância, que contribuem para atender a toda a demanda daqueles que não tinham condições de frequentar um curso presencial.

Outro avanço considerável é a implementação do Projeto Universidade Aberta do Brasil (UAB), criado em 2005 e oficializado em 8 de junho de 2006 pelo Decreto $n^{\circ} 5.800$, como consequência dos resultados positivos do Programa de Formação Inicial (Pró-Licenciatura). Costa e Zanatta (2010, p. 52) complementam esse dado, dizendo que:

\footnotetext{
Entre as finalidades do Sistema UAB, realçam-se as seguintes: (a) ampliar o acesso à educação superior pública; (b) reduzir as desigualdades de oferta de Ensino Superior entre as diferentes regiões do País; (c) estabelecer amplo sistema nacional de educação superior a distância; (d) fomentar o desenvolvimento institucional para a modalidade de educação a distância, bem como a pesquisa em metodologias inovadoras de Ensino Superior, apoiadas em tecnologias de informação e de comunicação.
}

Costa (2009) esclarece que o projeto de criação da UAB foi elaborado pelo Fórum das Estatais, que definiu a responsabilidade de cada organização vinculada a esse sistema. Assim, as universidades públicas têm como responsabilidade oferecer corpo docente qualificado, processos avaliativos, expedição dos documentos acadêmicos e atendimentos tutorias a distância. Aos municípios cabe oferecer 
infraestrutura local para o desenvolvimento das atividades presenciais obrigatórias. Os objetivos da UAB voltam-se para oferecer um ensino de qualidade, com a utilização das tecnologias de informação e comunicação (TICs). Apesar das grandes oportunidades propiciadas por esse sistema, destaca-se a necessidade de fiscalização constante do MEC e de órgãos competentes para que continue garantindo cursos de qualidade e contribuindo para a democratização da educação.

O principal instrumento de estudo da EaD é o computador e a internet; somente por meio dessas ferramentas é possível que os alunos dessa forma de ensino participem das atividades do Ambiente Virtual de Aprendizagem (AVA) propostas pelo curso, cuja característica primordial é a de superar a distância física entre docentes e discentes, garantindo a possibilidade de ensino-aprendizagem através de diversas tecnologias que propiciam a aquisição de conhecimento.

Os recursos tecnológicos existentes permitem à sociedade buscar informações em uma velocidade extraordinária. Nesse sentido, não é possível pensar em uma educação que não atenda aos novos princípios e necessidades dessa nova realidade mundial. A educação a distância se configura em uma das formas de acompanhar esse crescimento e desenvolvimento.

\section{DEFICIÊNCIA VISUAL E SUAS PRINCIPAIS CARACTERÍSTICAS}

Outra modalidade de ensino que vem se expandindo a cada dia é a Educação Especial. No Brasil, de acordo com Januzzi (1992), a iniciativa de oferecimento desse ensino ocorreu por parte das instituições particulares e oficiais, e os primeiros atendimentos aconteceram no Imperial Instituto dos Meninos Cegos, a partir do século XIX. A necessidade de se estabelecer uma política que amparasse esses indivíduos apenas foi alcançada com as leis criadas no país com a meta de assegurar a educação para todos. As discussões acerca desse assunto começaram no final do século XVIII e início do século XIX por meio dos movimentos sociais. Até então, a educação do deficiente se concentrava basicamente no ensino de trabalhos "manuais aos mesmos, na tentativa de garantir-lhes meios de subsistência e assim isentar o Estado de uma futura dependência desses cidadãos" (ZANFELICI, 2008, p. 2). 
A partir do século $X X$, observa-se um empenho em tornar a educação dos deficientes em algo que realmente desenvolva os conteúdos ministrados no ensino regular, deixando de ensinar apenas artesanatos ou quaisquer outras atividades consideradas fáceis.

As instituições de ensino devem buscar ensinar os conteúdos científicos para seu alunado com deficiência, considerando que se forem respeitadas as suas especificidades, eles serão capazes de aprender.

No passado, em razão das circunstâncias históricas e da falta de compreensão e estudos existentes na área, as pessoas com deficiência eram tratadas com desprezo, abandonadas em casas distantes das cidades, muitas eram assassinadas e outras deixadas à própria sorte. Em cada momento histórico, era agregada uma causa para as deficiências. Essas pessoas, muitas vezes, eram consideradas como possuídas pelo demônio ou ainda pagavam por um pecado grave cometido por seus pais. Antes do cristianismo, não eram tidas como humanas, pois acreditava-se que não tinham alma. Depois, passaram a ser consideradas filhas de Deus, mas ainda eram abandonadas pelas famílias devido a sua condição de nômades.

No século XVI, houve uma mudança na forma organizacional da sociedade, que passou a ser capitalista mercantil. A partir desse momento, várias ideias começaram a surgir sobre a deficiência; foram criados hospitais psiquiátricos que eram apenas lugares de confinamento e exclusão dos deficientes. No século XVIII, não havia respostas para as causas da deficiência, e as pessoas assim consideradas continuavam em locais de aprisionamento, como asilos e conventos.

Aranha (2001) destaca que apenas em 1800 surgiu, na Suíça, uma instituição que visava ao tratamento e cuidado dos deficientes, os quais, todavia, eram mantidos afastados da sociedade por estarem em tratamento.

O confinamento duradouro não permitia a essas pessoas inserir-se na sociedade, caso saíssem das instituições.

No Brasil, de acordo com Aranha (2001, p. 15):

Em qualquer área da atenção pública (educação, saúde, esporte, turismo, lazer, cultura) os programas, projetos e atividades são planejados para pessoas não deficientes. Quando abertos para o deficiente são, em geral, desnecessariamente segregados e/ou segregatórios, deixando para a 
pessoa com deficiência ou sua família quase que a exclusividade da responsabilidade sobre o alcance do acesso.

Com o passar do tempo, estudos foram desenvolvidos a fim de entender a pessoa com deficiência. As políticas públicas de cada país também foram alteradas de modo a contribuir para o processo de aceitação dessas pessoas como integrantes de uma sociedade, e as regulamentações da educação especial passaram a ser mais bem consideradas pelos países.

No Brasil, a regulamentação da educação especial se inicia com a LDB 9394/96, que estabelece a educação como direito de todos e dever do Estado.

Lima (2006) registra que oferecer o ensino às crianças com deficiências ou necessidades educativas especiais é um compromisso estabelecido com o atendimento às necessidades educacionais deles e à qualidade de ensino.

Nas últimas décadas, houve grandes avanços sobre o respeito à diversidade como consequência das discussões sociais envolvendo esse tema. Salienta-se que a realidade atual ainda não é a ideal, mas, no que se refere às políticas públicas, muito se tem feito para que as pessoas com deficiência ou necessidades educativas especiais possam se sentir cada vez mais respeitadas e inseridas na sociedade. Acerca dessa questão, Lima (2006, p. 33) destaca:

Percebemos que a sociedade brasileira está vivendo um processo inédito. Nas cidades do início do século XXI, encontramos pessoas com deficiências frequentando escolas, os mais diversos ambientes de trabalho, supermercados e lojas, e ainda participando de competições esportivas. Isso não ocorria há 20 anos.

Em especial, a educação de alunos com deficiência visual é um grande desafio a todos, tanto para a sociedade, quanto para os professores que, com base na legislação vigente, devem oferecer um ensino de qualidade a todos. Para entender melhor o deficiente visual, é necessário entender alguns aspectos e características dessa deficiência.

Sá, Campos e Silva (2007, p. 15) discorrem sobre o que se pode entender por deficiência visual:

A cegueira é uma alteração grave ou total de uma ou mais das funções elementares da visão que afeta de modo irremediável a capacidade de 
perceber cor, tamanho, distância, forma, posição ou movimento em um campo mais ou menos abrangente. Pode ocorrer desde o nascimento (cegueira congênita), ou posteriormente (cegueira adventícia, usualmente conhecida como adquirida) em decorrência de causas orgânicas ou acidentais. Em alguns casos, a cegueira pode associar-se à perda da audição (surdocegueira) ou a outras deficiências. Muitas vezes, a perda da visão ocasiona a extirpação do globo ocular e a consequente necessidade de uso de próteses oculares em um dos olhos ou em ambos. Se a falta da visão afetar apenas um dos olhos (visão monocular), o outro assumirá as funções visuais sem causar transtornos significativos no que diz respeito ao uso satisfatório e eficiente da visão.

A baixa visão ou visão subnormal, como também é conhecida, é considerada deficiência visual. No Caderno da TV Escola elaborado pelo MEC em parceria com a Secretaria de Educação a Distância (BRASILIA, 2000, p. 6), a baixa visão é definida como:

[...]alteração da capacidade funcional decorrente de fatores como rebaixamento significativo da acuidade visual, redução importante do campo visual e da sensibilidade aos contrastes e limitação de outras capacidades.

Assim as pessoas com deficiência visual tendem a ter mais dificuldades que as demais em relação aos estímulos visuais. Lima (2006, p. 77) destaca que "a falta de visão afeta algumas atividades específicas, sendo a mais importante de toda a movimentação no espaço físico. O acesso, por meio da leitura, à informação escrita também deve ser destacado".

A sociedade atual se desenvolve em um sistema capitalista e consumista, que busca despertar o interesse das pessoas pelos aspectos visuais, tais como conquistar os clientes pela beleza do produto, vender pela propaganda que mais chama a atenção, escolher a comida pelos pratos mais bonitos aos olhos do cliente. Dessa forma, os estímulos visuais são prioridades na sociedade quando sua intenção é vincular informações.

A linguagem, a comunicação e as múltiplas formas de expressão cultural ou artística constituem-se de imagens e apelos visuais cada vez mais complexos e sofisticados. Os conteúdos escolares privilegiam a visualização em todas as áreas de conhecimento, de um universo permeado de símbolos gráficos, imagens, letras e números. Assim, necessidades decorrentes de limitações visuais não devem ser ignoradas, negligenciadas ou confundidas com concessões ou necessidades fictícias. Para que isso não ocorra, devemos ficar atentos em relação aos nossos conceitos, preconceitos, gestos, atitudes e posturas com abertura e disposição para rever as práticas convencionais, conhecer, reconhecer e 
aceitar as diferenças como desafios positivos e expressão natural das potencialidades humanas. (SÁ; CAMPOS; SILVA, 2007, p. 13)

Nesse sentido, no que se refere à pessoa com deficiência visual, deveriam ser utilizados recursos auditivos e táteis, a fim atender às suas necessidades. $A$ utilização de recursos que venham ao encontro dessa nova realidade social de inclusão e respeito é uma forma consciente e importante de inserir de forma literal os deficientes em um mundo feito para e por videntes, mudando a postura de olhar, entender e de relacionar-se com esses indivíduos.

Ao pensar na EaD, as práticas pedagógicas direcionadas ao aluno deficiente visual giram em torno dessa discussão, a qual prevê a necessidade de utilizar estratégias que o atinja de forma plena para que possa participar plenamente de um curso nessa modalidade.

No que se refere à educação, Lima (2006) destaca como o processo educacional pode acontecer em um ambiente escolar com alunos com deficiência visual. Segundo a autora, a educação desses alunos é possível, mas é preciso usar estratégias e ferramentas adequadas para cada especificidade.

A educação de pessoas com deficiências visuais exige alguns recursos específicos que viabilizem seu acesso ao mundo cultural e científico. Esses recursos podem estar associados à educação que ocorre na escola comum, e envolvem desde aspectos cotidianos das relações interpessoais até o uso do computador como ferramenta indispensável. (LIMA, 2006, p. 93)

Dessa forma, pode-se pensar em um processo educacional responsável pelo desenvolvimento real desse alunado, fazendo com que todo esse processo de aprendizagem contribua positivamente para sua vida social e pessoal e, por consequência, atenda às legislações vigentes.

Como Kenski (2003, p. 26) coloca, "no atual estágio da sociedade, o homem encontra-se diante de um modelo totalmente novo de organização social, baseado na combinação da tecnologia da informação e da comunicação, cuja substância e matéria-prima é totalmente invisível: informação". Para que o deficiente visual possa ter acesso à informação, os meios de comunicação presentes na sociedade necessitam pensar na vinculação dessas informações com mecanismos que 
também o atendam, respeitando sua deficiência para que possa ter acesso a tais informações.

Schlunzen (2005) ressalta o quanto a tecnologia contribui para o processo educacional dos alunos e, no caso de alunos com alguma deficiência, essa mesma tecnologia seria um meio/recurso que poderia transformar a vida dessas pessoas para melhor.

Com o avanço das tecnologias de informação e comunicação, os professores têm papel fundamental na mediação do trabalho pedagógico associado a esses recursos.

[...] a educação torna-se ação estratégica para a construção de uma nova ordem social em que a exclusão (em princípio, do acesso, do consumo, da ideologia capitalista vigente) não tenha espaço.

A educação neste momento pode, portanto, cooptar, no sentido de abraçar as novas tecnologias como o caminho natural para estar de acordo com os valores e padrões estabelecidos pela nova ordem internacional ou entender as novas tecnologias como espaço de luta e de transformação. (KENSKI, 2003, p. 30-31)

Cabe ao professor e a todos os envolvidos no processo educacional apropriar-se das novas tecnologias de informação e comunicação utilizando no processo de desenvolvimento e aprendizagem do aluno. Essa interação, juntamente com a mediação recebida, será um avanço no processo educacional e de desenvolvimento das pessoas com necessidades educativas especiais, propiciandoIhes oportunidades para trilharem seu próprio caminho de forma independente, com autonomia e conhecimento.

A pessoa com deficiência visual é capaz de aprender como qualquer outra; ela precisa, entretanto, de propostas pedagógicas que considerem suas especificidades. Aos poucos, como aconteceu com as outras deficiências na história da educação especial, a deficiência visual foi alcançando espaço e respeito. Sabese que esse processo ainda é demorado, pois ainda há descaso na educação de todos, seja destinada a indivíduos com necessidades educativas especiais ou não.

No encontro entre governos e organizações internacionais realizado no ano de 1994, em Salamanca, Espanha, reafirmou-se o compromisso de educação para todos, visando principalmente à educação das pessoas com necessidades 
educativas especiais; desse encontro surgiu o documento conhecido como Declaração de Salamanca.

O compromisso do Estado é providenciar condições para que tais alunos possam frequentar a rede regular de ensino de forma que os mesmos tenham nível adequado de aprendizagem, programas e sistemas educacionais que atendam às especificidades, centros educacionais centrados neles, escolas regulares que possuam orientações inclusivas, de forma que a sociedade com o tempo adote a prática inclusiva em todos os seus segmentos.

Para Goés (1996, p. 35, grifos do autor):

A deficiência não torna a criança um ser que tem possibilidades a menos; ela tem possibilidades diferentes. Dessa perspectiva, a deficiência não deve ser concebida como uma falta ou fraqueza, já que o indivíduo pode encontrar, a partir das relações sociais, outras formas de desenvolvimento com base em recursos distintos daqueles tipicamente acessíveis na cultura. Por isso, o diagnóstico e o planejamento educacional devem orientar-se para os pontos fortes da criança, e não para a falta.

Nesse sentido, o desenvolvimento educacional dos alunos com deficiência visual, independente do nível escolar, será consequência da mediação exercida pelos profissionais da educação, por meio das estratégias, recursos pedagógicos e didáticos que irão proporcionar a estes alunos. Assim, os objetivos alcançados serão os mesmos que os direcionados aos alunos videntes. A diferença deste processo será a forma como o Núcleo Educacional da instituição de ensino olhará para o aluno cego ou com baixa visão.

Um grande estudioso sobre a aprendizagem da criança deficiente foi Vygotsky. Nuernberg (2006) destaca que Vygotsky faz uma crítica ao processo educacional e social vivenciado em sua época, dividindo a deficiência em duas, uma denominada deficiência primária e a outra deficiência secundária. A primária referese às limitações que a deficiência em si causa; a secundária é a deficiência que a sociedade cria e elabora a cada dia, excluindo as pessoas com alguma deficiência do convívio social.

Essas limitações secundárias, portanto, são mediadas socialmente, remetendo ao fato de o universo cultural estar construído em função de um padrão de normalidade que, por sua vez, cria barreiras físicas, educacionais e atitudinais para a participação social e cultural da pessoa com deficiência. 
(...) Cria-se, assim, um círculo vicioso no qual, ao não se acreditar na capacidade de aprender das pessoas com deficiência, não lhe são ofertadas condições para superarem suas dificuldades. Em consequência, elas ficam condenadas aos limites intelectuais inerentes à deficiência, tomados assim como fatos consumados e independentes das condições educacionais de que dispõem. (NUERNBERG, 2006, p. 309).

Vygotsky afirma que a mediação é um instrumento fundamental para que os alunos alcancem a aprendizagem. Para isso ser possível, é necessário que esta mediação seja desenvolvida a partir das necessidades individuais de cada aluno. Nesse âmbito, a aprendizagem do deficiente visual é possível desde que sejam atendidas suas necessidades de aprendizagem; as tecnologias têm contribuído nesse processo principalmente por apresentarem recursos sonoros e táteis. Em função disso, apresentar-se-á, em seguida, como a EAD contribui nesse processo de ensino-aprendizagem da pessoa deficiente visual.

\section{EDUCAÇÃO A DISTÂNCIA E SUA RELAÇÃO COM O ALUNO DEFICIENTE VISUAL}

A EaD passou a ser regulamentada a partir da LDB 9394/96, com o principal objetivo de ofertar um ensino de qualidade e acesso para todos. $O$ direito de estudar em instituições regulares de ensino foi adquirido pelo deficiente também a partir da LDB 9394/96.

No campo da educação especial, a EaD passou a ser inclusiva, de forma a proporcionar o acesso à educação para todos como previsto na lei.

A dificuldade, seja no ensino presencial ou a distância, sempre existirá devido às especificidades de cada um. O importante é destacar, aqui, que os órgãos públicos, assim como a sociedade, têm procurado amenizar os problemas encontrados em busca de uma educação que respeite as diferenças e atenda às necessidades de aprendizagem desses alunos.

O atendimento dos deficientes visuais na educação a distância é possível também pela existência dos softwares a eles direcionados, como, por exemplo, os seguintes programas que auxiliam na leitura de textos: DOSVOX, BR Braille, Braille Creator, Braille Fácil, Dolphin, Jaws, Openbook, Pocket Voice, Slimware Window Bridge, Tecla fácil, Teclado falado, Virtual Vision, WAT e Windows-Eyes. 
O sistema DOSVOX é o mais utilizado pelos brasileiros cegos, tendo sido criado no Brasil pelo Núcleo de Computação Eletrônica da UFRJ e aprimorado pelo estudante cego de informática, Marcelo Pimentel Pinheiro, a fim de auxiliar os deficientes visuais no manuseio do computador. O sistema permite a leitura de textos definidos, a edição de textos e possibilita a utilização de elementos como calculadora e jogos por intermédio de um sintetizador de som. Esse sistema é utilizado por mais de 500 cegos no Brasil, tem baixo custo, é fácil de ser manuseado, o idioma utilizado é o português e o processo de produção é simples (BORGES, 2005).

De acordo com Machado (2011), a educação a distância e sua relação com a educação inclusiva do deficiente visual é uma forma de contribuição para o processo de crescimento da sociedade.

Este fato vem sendo fundamental para o avanço da sociedade contemporânea na luta contra a discriminação, pois auxilia na valorização e inclusão das pessoas com deficiência visual, aumentando suas possibilidades de desenvolvimento profissional, produtivo e promovendo sua integração social mais digna. (MACHADO, 2011, p. 114)

O aluno deficiente visual encontra diversas dificuldades para desenvolver suas ações pela falta da visão. Isso não significa, porém, que não pode aprender, já que ele utilizará de estratégias que facilitam sua aprendizagem.

A maior dificuldade está no acesso às informações, pois, muitas vezes, esse aluno depende da ajuda de terceiros para aprender a viver em sociedade, contribuindo para seu processo de desenvolvimento e para que atue de forma produtiva em sua comunidade.

A sociedade se diz inclusiva, mas nem sempre são observadas acessibilidade e cooperação entre as pessoas de forma satisfatória, a fim de atender às especificidades dos deficientes. Nesse contexto, destacam-se as possibilidades de acesso que a EaD proporciona a esses alunos, quando favorece o processo de aprendizagem e contribui para a sua formação profissional. De acordo com Machado (2011, p. 117):

As pessoas com deficiência perceberam na EAD uma oportunidade de realizar seus estudos, em casa, excluindo, portanto, as barreiras de 
locomoção e arquitetônicas que existem para cursar seus estudos em muitas escolas, recebendo maior acesso aos materiais didáticos e facilidade de comunicação com o corpo docente.

Mesmo estando separados fisicamente, alunos e professores, alunos e alunos, são capazes de interagir e trocarem informações e conhecimentos, permitindo, assim, uma integração e aquisição de conhecimento real, em ambiente virtual.

Esses aspectos evidenciam possibilidades de crescimento, acessibilidade e inclusão proporcionados pela EaD para o processo de desenvolvimento e aprendizagem do deficiente visual. Existem, contudo, pontos negativos desse processo.

Se, por um lado, os alunos se encantam e são contemplados em algumas expectativas; por outro, são prejudicados pela falta de mediação adequada dos professores e tutores, pois, para alcançar os objetivos propostos, o professor precisa planejar sua aula de forma que atinja todos os alunos. Na educação a distância esse aspecto não é diferente; cabe ao professor, então, utilizar metodologias diferentes que atendam a todos os alunos, principalmente quando um deles tem deficiência visual.

Assim, com todas as transformações sociais, educacionais e o direito de educação para todos, é comum observar pessoas com algum tipo de deficiência frequentando os níveis superiores, bem como cursos de educação a distância, os quais atendem a uma grande demanda de estudantes. No caso de alunos com deficiência visual, matriculados regularmente nos cursos de EaD, apresenta-se o seguinte questionamento: como se dá todo processo educacional desses alunos e quais as estratégias e mediações necessárias para atender às suas especificidades?

Pensando nesse aluno, o professor, o tutor presencial ou a distância deverão atender às necessidades desse alunado a partir do que eles dominam, seja por meio de programas que leem o texto selecionado, de conferências nas quais a audição seria o meio de aquisição de conhecimentos ou com a disponibilização de materiais em Braille para impressão.

O importante é oferecer educação de qualidade incluindo esses alunos em uma sociedade que está em processo de transformação. Conforme Nuernberg (2006, p. 313), Vygotsky afirma que o caminho para o desenvolvimento de um aluno 
cego é a mediação exercida em seu processo de aprendizagem. E, para Meier e Garcia (2008, p. 72):

A concepção da mediação, como possibilitadora da construção pessoal do conhecimento, deve trazer consigo algumas mudanças na ação do professor. Posturas não mediadoras precisam ser revistas, integradas e contextualizadas. Há que se promover transformações no trabalho docente que garantam a mediação da aprendizagem como opção consciente de ação pedagógica ou, por que não dizer, andragógica. $O$ fator de "construção" como parte integrante e integradora do conceito de mediação da aprendizagem é um passo necessário nesse caminho.

A mediação adequada não se conquista em pouco tempo. É consequência do processo de formação e trabalho desenvolvido pelo professor em questão. A mediação é um aspecto a ser planejado e repensado quantas vezes forem necessárias a fim de ajudar os alunos.

Nuernberg (2006, p. 304) ressalta que:

[...] cumpre ainda ressaltar que o objetivo da educação de pessoas com deficiência visual deve ser o mesmo de pessoas videntes. A despeito de conquistarem esse objetivo por vias alternativas, em razão de suas necessidades educativas específicas - como é o caso da aprendizagem da simbologia Braille para aquisição da escrita e da leitura -, cabe oferecer aos educandos cegos as mesmas oportunidades e exigências que são proporcionadas ou feitas aos demais alunos. Para tanto, valorizar suas experiências táteis, auditivas e cinestésicas é tão importante quanto proporcionar intervenções que favoreçam a formação de conceitos por meio dos processos de significação, promovendo assim o desenvolvimento das funções psicológicas superiores.

O deficiente visual, em um curso a distância, está privado de algumas atividades que poderiam ser realizadas em sala de aula, mas o mesmo acontece com alunos que não possuem nenhum tipo de deficiência. Ou seja, o aluno, deficiente ou não, deverá ter mediações e recursos alternativos para aprender em um curso a distância. O resultado desse estudo se dará a partir da responsabilidade e comprometimento de cada aluno e do trabalho realizado pelo professor.

O professor encontrará desafios em mediar os conteúdos, sendo extremamente importante que o professor converse com seu aluno sobre os materiais e recursos tecnológicos que ele domina, para facilitar o planejamento do curso e o direcionamento das atividades. É fundamental disponibilizar ao longo das aulas materiais didáticos adaptados as suas necessidades. 
De acordo com Rodrigues e Barni (2009, p. 3), os recursos tecnológicos que podem contribuir para o processo de aprendizagem do aluno com deficiência visual são:

\begin{abstract}
Material pedagógico ampliado ou em relevo; impressão em Braille, lupas, teclados especiais, software com acessibilidade. Recebem todo o material didático e livros em CD digital, com os quais realizam a leitura com a ajuda do Software Jaws e DOSVox.

Os alunos também utilizam o ambiente virtual de aprendizagem (AVA), é um recurso tecnológico que permite a interação entre professores e alunos em diferentes localidades, e de maneira síncrona e assíncrona. Dentre os mais utilizados atualmente pode-se citar o Moodle, o Claroline, o Solar, o TelEduc.
\end{abstract}

O professor deve ser capaz de mediar o processo de aprendizagem de forma que o aluno seja autônomo para estudar e não dependente de uma terceira pessoa para ajudar a desenvolver as atividades solicitadas. Ao utilizar recursos audiovisuais, de acordo com Rodrigues e Barni (2009, p. 7), o professor "deve descrever as imagens de modo que tenham significado e sentido para o aluno com deficiência visual ou com visão reduzida, contribuindo para a compreensão do conteúdo trabalhado, buscando, assim, garantir os objetivos propostos".

O processo de mediação deve desenvolver potencialidades e autonomia no aluno para que este encontre estratégias de aprendizagem favoráveis as suas especificidades. Na relação entre professor-aluno e aluno-professor, o objetivo maior é facilitar o processo de aprendizagem do aluno com deficiência visual em todos os aspectos educacionais.

\title{
4 CONSIDERAÇÕES FINAIS
}

A educação a distância para alunos com deficiência visual se torna um aspecto importante na luta pela acessibilidade e educação para todos. Esse processo é um avanço fundamental, em que os alunos cegos ou com baixa visão são capazes de frequentar cursos a distância sem ser prejudicados. É importante ressaltar que isto apenas é possível pelo domínio desses recursos por parte dos alunos com necessidades educativas visuais, pois, se não houver o domínio da 
utilização e adequação do computador, por exemplo, será necessária outra pessoa que auxilie o aluno no uso dessas ferramentas.

Assim, a EaD contribui para os processos de ensino e de aprendizagem dos alunos, porque disponibiliza recursos que facilitam o alcance desses processos, promovendo independência e formação profissional. Contudo, ainda existem dificuldades devido à falta de mediação do professor, tutor a distância e presencial, porque, muitas vezes, estes desconhecem as especificidades de seus alunos. Além disso, falta formação a estes quanto ao atendimento das necessidades educacionais de alunos com deficiência visual. Como citado anteriormente, faz-se necessário que esses profissionais da educação revejam suas práticas bem como suas ações no que diz respeito ao atendimento da pessoa deficiente em busca da construção de uma educação inclusiva, seja ela na modalidade a distância ou presencial.

A sociedade, aos poucos, tem percebido a importância da inclusão dos deficientes. Esse processo pode ser lento, mas os avanços alcançados tornam a vida dessas pessoas mais fácil. As oportunidades estão aparecendo, proporcionando condições de vida e de desenvolvimento para essa parte da população. A educação a distância abre caminhos para a educação chegar a eles, permitindo, por meio de sua estrutura educacional, o acesso à educação de qualidade.

A modalidade a distância existe para que o acesso seja para todos, mas existem dois aspectos que necessitam de mudanças na postura dos envolvidos: o primeiro está relacionado à formação dos profissionais da educação, que necessitam de especializações direcionadas ao atendimento desses alunos. $O$ segundo aspecto diz respeito à pouca procura de cursos na modalidade EaD por alunos deficientes no Brasil.

Essa relação da educação especial e educação a distância é uma forma de demonstrar que o acesso à educação depende de ações, estruturas e instituições que estejam preocupadas com desenvolvimento das pessoas, de modo que esse acesso à educação seja pleno, independente das características da população. Educação de qualidade é uma garantia de todos; é necessário que as pessoas com deficiência também busquem essa educação de qualidade, pois, dessa forma, 
espera-se que sejam desenvolvidas novas ações de inclusão e melhorias no processo educacional e no acesso a este.

\section{MARIA LUISA FURLAN COSTA}

Doutora em Educação pela Universidade Estadual Júlio de Mesquita Filho (Unesp/Araraquara). Mestre em Educação pela Universidade Estadual de Maringá (UEM). Graduada em História pela UEM. Professora do Departamento de Fundamentos da Educação e do Programa de Pós-Graduação em Educação da UEM.

\section{TAISSA VIEIRA LOZANO}

Especialista em Educação Especial pela Universidade Estadual de Maringá (UEM). Graduada em Pedagogia pela UEM. Professora da rede particular de ensino Maringá/PR.

\section{REFERÊNCIAS}

ALVES, L.; NOVA, C. Educação a distância: limites e possibilidades. In: ALVES, L.; NOVA, C.. (orgs). Educação a distância: Uma nova possibilidade de aprendizado e interatividade. São Paulo: Futura, 2003, p.1-23.

ARANHA, M. S. F. Paradigmas da relação da sociedade com as pessoas com deficiência. Revista do Ministério Público do Trabalho, Ano XI, nº. 21, março, 2001, p.160-173.

BACHA FILHO, T. Educação a distância, sistemas de ensino e territorialidade. In: FRAGALE FILHO, R.. Educação a distância: análise dos parâmetros legais e normativos. Rio de Janeiro: DP\&A, 2003, p.27-42.

BORGES, J. A. O sistema DOSVOX. [S.I.:s.n], 2005. Disponível em: <http://www.ibc.gov.br/?itemid=100>. Acesso em 17 nov. 2011.

BRASÍLIA. GIL, M. (org.). Deficiência visual. Brasília: Ministério da Educação; Secretaria de Educação a Distância, 2000. Disponível em: $<$ http://portal.mec.gov.br/seed/arquivos/pdf/deficienciavisual.pdf >. Acesso em 27 out. 2013.

INSTITUTO NACIONAL DE ESTUDOS E PESQUISAS EDUCACIONAIS ANÍSIO TEIXEIRA. Censo da educação superior: 2010 - Resumo Técnico. Brasília: Instituto Nacional de Estudos e Pesquisas Educacionais Anísio Teixeira, 2012. Disponível em:

http://download.inep.gov.br/educacao superior/censo superior/resumo tecnico/resu mo tecnico censo educacao superior 2010.pdf>. Acesso em: 21 out. 2012. 
COSTA, M. L. F. O sistema Universidade Aberta do Brasil: democratização e interiorização do ensino superior. In: COSTA, M. L. F.(org) Introdução à educação a distância. Maringá: Eduem, 2009.

COSTA, M. L. F.; ZANATTA. R. M. Educação a distância no Brasil: programas do ministério da educação. In: COSTA, M. L. F.; ZANATTA, R. M. (orgs.). Educação a distância no Brasil: aspectos históricos, legais, políticos e metodológicos. 2. ed. Maringá: Eduem, 2010. p.43-55.

GOÉS, M. C. R. Linguagem, surdez e educação. Campinas, SP: Autores Associados, 1996. 97p.

JANUZZI, G. A Luta pela Educação do Deficiente Mental no Brasil. 2. ed. Campinas, SP: Editora Autores Associados, 1992. 123p.

KENSKI, V. M.. Novas Tecnologias na Educação Presencial e a Distância. In: ALVES, L.; NOVA, C. Educação a Distância: uma nova concepção de aprendizado e interatividade. São Paulo: Futura, 2003, p.25-42.

LIMA, P. A. Educação inclusiva e igualdade social. São Paulo: Avercamp, 2006.

MACHADO, C. D. C.. A inclusão da pessoa com deficiência visual na escola: contribuições da Educação a Distância. In: Educação a distância: revista científica. Batatais, v. 1, n. 1, 2011. p.113-121. Disponível em: http://sm.claretiano.edu.br/upload/4/revistas/pdf/3.pdf. Acesso em: 10 out. 2011.

MEIER, M.; GARCIA, S.. Mediação da aprendizagem: contribuições de Feurstein e de Vygotsky. Curitiba: Edição do autor, 2007. 212.

NUERNBERG, A. H.. Contribuições de Vigotski para a educação de pessoas com deficiência visual. Psicologia em Estudo. Maringá, v.13, n.2, p.307-316, abr./jun. 2008.

RODRIGUES, K. G.; BARNI, E. M. A utilização de recursos tecnológicos com alunos deficientes visuais no curso superior a distância de uma instituição de ensino de Curitiba-Pr. [S.I.:S.n] 2009 Disponível em: < http://www.pucpr.br/eventos/educere/educere2009/anais/pdf/3537 2058.pdf $>$. Acesso em 03 mar. 2011.

SÁ, E. D.; CAMPOS, I. M.; SILVA, M. B. C. Atendimento Educacional Especializado: deficiência visual. Brasília: Cromos, 2007. Disponível em: <http://portal.mec.gov.br/seesp/arquivos/pdf/aee dv.pdf> Acesso em: 08 mar. 2011.

SCHLUNZEN, E. T. M. A tecnologia para inclusão de Pessoas com Necessidades Especiais (PNE). In: PELLANDA, N. M. C.; SCHLUNZEN, E. T. M.; JUNIOR, K. S. (orgs.). Inclusão digital: tecendo redes afetivas/cognitivas. Rio de Janeiro: DP\&A, 2005. p. 195-210. 
ZANATTA. R. M. Educação a distância no Brasil: aspectos legais. In: COSTA, M. L. F.; ZANATTA, R. M. (orgs.). Educação a distância no Brasil: aspectos históricos, legais, políticos e metodológicos. 2. ed. Maringá: Eduem, 2010. p.24-42.

ZANFELICI, T. O. Resenha. Curitiba:[s.n.], 2008. Disponível em: $<$ http://www.scielo.br/scielo.php?pid=S0104-

40602008000200017\&script=sci arttext>. Acesso em: 14 jul. 2011. 